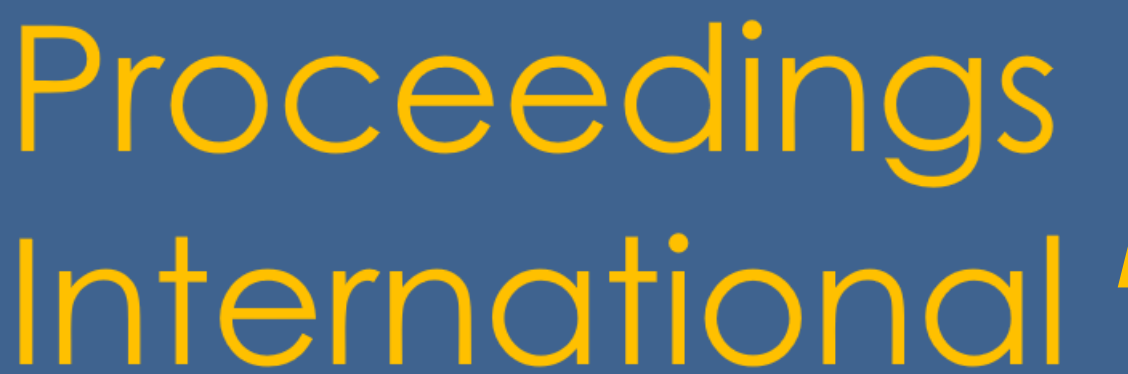

Volume 1, Issue 1, Pages 0058-0059

\title{
Study of the interface area in the metalo-ceramic prosthetic restorations by Scanning Electron Microscopy (SEM) and EDS Analysis
}

\author{
V. G. Vasilescu ${ }^{1}$, E. Vasilescu 2,* \\ 1 "Carol Davila" University of Medicine and Pharmacy, Faculty of Dental Medicine, Bucharest, Romania \\ 2 Dunărea de Jos" University of Galați, Romania \\ * Correspondence: elisabeta.vasilescu@ugal.ro; Scopus ID: 56275806400
}

The research of the metal-ceramic bond and the evaluation of its quality is possible through indirect non-destructive methods, which conclusively complete the mechanical tests to measure the shear resistance. The quality of the restorations in which the chemical adhesion is the mechanism with defining role on the nature of the metal-ceramic bond is achieved mainly by the appearance of an oxide layer formed by the elements in the composition of the alloys.

The oxide layer ensures the oxygen bridges, the diffusion of the metal ions into the ceramic mass, the creation of the necessary conditions for the chemical reactions at the metal-ceramic interface. However, the thickness of the oxide layer is an important parameter, which controls the quality of the resistance of the metal-ceramic bond. The analysis of the interface area by scanning electron microscopy (SEM) and the EDS analysis allowed the examination of both components and provided information on the type of rupture when the ceramic was removed from the metallic substrate, the compositional nature in the interface area, the presence of the oxide layer and of its characteristics.

The experimental results obtained confirm some results from the literature on the behavior of the noble alloys as substrates in the metal-ceramic restorations.

Keywords: SEM, EDS, metalo-ceramic prosthetic, restoration, oxide layer.

\section{Funding}

Not applicable.

\section{Acknowledgments}

Not applicable.

\section{Conflicts of Interest}

The authors declare no conflict of interest. 

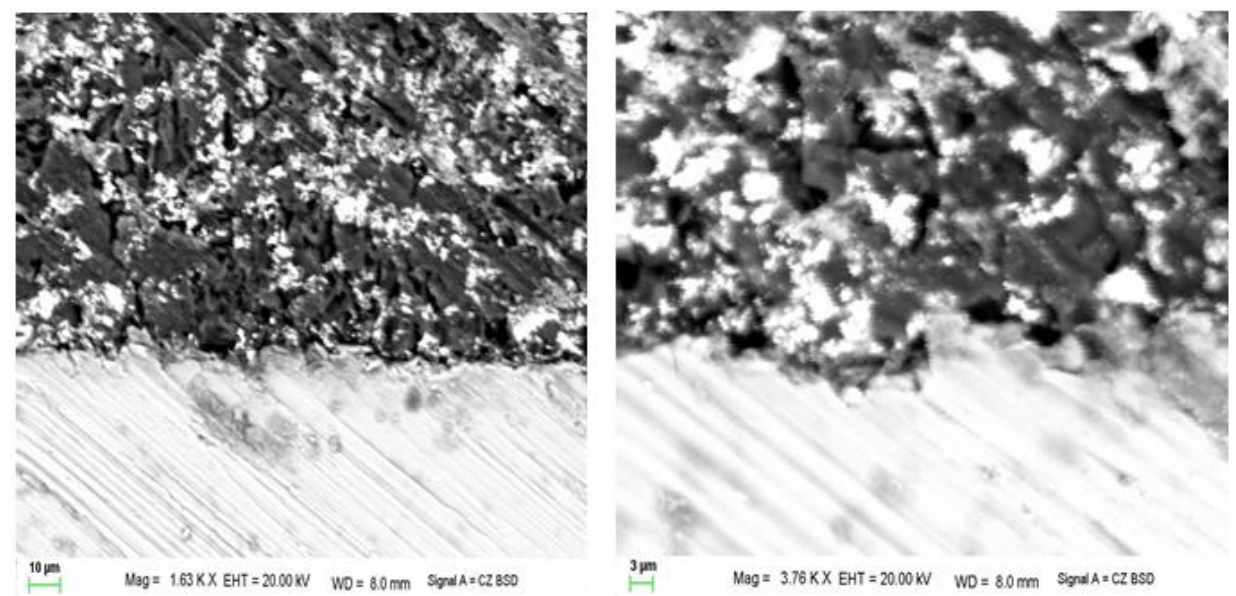

Figure 1. Microstructural Aspects of the Metal-Ceramic Interface Zones (Tigrade4 substructure).
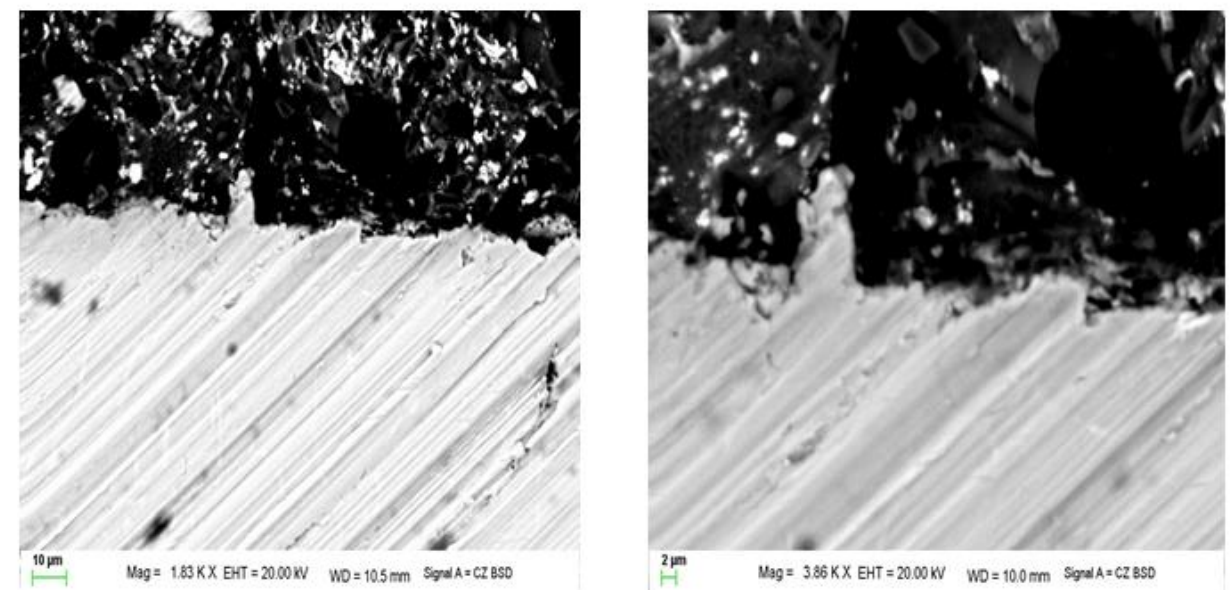

Figure 2. Microstructural Aspects of the Metal-Ceramic Interface zones (Ti10Zr substructure).

\section{References}

1. Craig, R.G.; Powers, J.M. Restorative Dental Materials, Eleventh Ed., ISBN 0-323-01442-9 1, 1997.

2. Lütjering, G.; Williams, J.C. Titanium industry status. In: Titanium Alloys, Springer, 2003.

3. Rack, H.J.; Qazi, J.I. Titanium alloys for biomedical applications, Materials Science and Engineering C Volume 26,
Elsevier, 2006; pp. $1269 \quad$ - 1277 , https://doi.org/10.1016/j.msec.2005.08.032.

4. Vasilescu, E.; Vasilescu, V.G.; Patrascu, I. Researches regarding the metalo - ceramic bonding in prosthetic restorations with titan and titan alloys metallic component. Romanian Journal of Materials 2019, 49. 12-22, 2019.

(C) 2019 by the authors. This article is an open access article distributed under the terms and conditions of the Creative Commons Attribution (CC BY) license (http://creativecommons.org/licenses/by/4.0/). 